\title{
La Nueva Organización Anticomunista (NOA). Historia represiva de un escuadrón de la muerte paraestatal
}

\section{Carlos Fernando López de la Torre ${ }^{1}$}

Recepción: 23 de junio de 2017 / Aceptación: 6 de noviembre de 2017

\section{Resumen}

El artículo examina la historia de la Nueva Organización Anticomunista (NOA), un escuadrón de la muerte paraestatal que existió en Guatemala entre 1967 y 1968, teniendo como objetivo central el análisis de la violencia política y, específicamente, del papel que ejerció en la represión de las disidencias políticas de la época. Para cumplir con tal propósito, se plantea, en primer término, un abordaje teórico que busca definir las características de los escuadrones como actores represivos. A continuación, se presenta el contexto y desarrollo del complejo contrainsurgente represivo que dio origen a la NOA durante la presidencia de Julio César Méndez Montenegro (1966-1970). Posteriormente y con base en fuentes de época y bibliografía especializada, se traza el devenir de la organización, atendiendo sus objetivos, composición social, mecanismos de actuación y repercusiones de sus crímenes. La investigación muestra cómo la violencia de la NOA fue capital en la propagación del terror a finales de la década de 1960 y en el desarrollo de un consenso conservador que posibilitó el retorno de los militares a la presidencia nacional en 1970; razones que resaltan la importancia de atender el conflicto armado interno partiendo del estudio de los llamados perpetradores.

\section{Palabras clave}

Nueva Organización Comunista (NOA); represión; violencia política; anticomunismo; Centroamérica

\section{Abstract}

The article examines the history of the New Anti-Communist Organization (NOA), a parastatal death squad that existed in Guatemala between 1967 and 1968, with the main purpose of analyzing political violence and, specifically, the role it played in repression of the political dissidents of the time. In order to fulfill this purpose, a theoretical approach is proposed, which seeks to define the characteristics of the squads as repressive actors. The context and development of the repressive counterinsurgency complex that gave rise to NOA during the presidency of Julio César Méndez Montenegro (1966-1970) is

1 Mexicano. Maestro en Estudios Latinoamericanos por la Universidad Nacional Autónoma de México. Actualmente es doctorando en el programa de Historia Moderna y Contemporánea en el Instituto de Investigaciones Dr. José María Luis Mora. Correo electrónico: cflopezt@institutomora.edu.mx 
then presented. Subsequently, and based on sources and specialized bibliography, the article traces the future of the organization, according to its goals, social composition, mechanisms of action, and the consequences of its crimes. The research shows how the violence of the NOA was central to the spread of terror in the late 1960s and in the development of a conservative consensus that made possible the return of the military to the presidency in 1970; reasons that highlight the importance of approaching the internal armed conflict from the study of the so-called perpetrators.

\section{Keywords}

New Communist Organization (NOA); repression; political violence; anticommunism; Central America

\section{Resumo}

O artigo examina a história da Nova Organizaçao Anticomunista (NOA), um esquadrão da morte paraestatal que existiu em Guatemala entre 1967 e 1968, tendo como objetivo central o análise da violência política e, especificamente, o papel que desempenhava na repressão da dissidência política da época. Para cumprir com esse propósito, propõe-se, em primer lugar, uma abordagem teórica que procura definir as características das esquadras como actores repressivos. Depois, presenta-se o contexto e desenvolvimento do complexo da contra-insurgência repressiva que deu origem à NOA durante o governo de Julio César Méndez Montenegro (1966-1970). Posteriormente e com base em fontes da época e bibliografía especializada, trazase a evolução da organização, atendendo os seus sus objetivos, composição social, mecanismos de ação o impacto dos seus crimes. A pesquisa mostra como a violência da NOA foi fundamental para a propagação do terror no final da década de 1960 e no desenvolvimento de um consenso conservador que possibilitou o retorno dos militares à presidência nacional em 1970; razões que destacam a importância de abordar o conflito armado interno desde o estudo dos chamados perpetradores.

\section{Palavras chave}

Nova Organização Comunista (NOA); repressão; violência política; anticomunismo; América Central

\section{Presentación}

El presente artículo ofrece un acercamiento a la historia de la Nueva Organización Anticomunista (NOA), un escuadrón de la muerte paraestatal que operó en Guatemala entre 1967 y 1968. El interés central de la investigación es identificar la trayectoria, objetivos y mecanismos de actuación que convirtieron a la NOA en un actor relevante de la represión político-social que vivió la nación centroamericana durante el desarrollo del conflicto armado interno, a finales de la década de 1960. Con este abordaje, se pretende profundizar en el conocimiento histórico de la violencia política guatemalteca, al atender a los llamados perpetradores y al buscar comprender la racionalidad detrás 
de sus acciones y los móviles que los impulsaron a cometer diversos crímenes violatorios de los derechos humanos.

Para cumplir con los propósitos señalados, el artículo se divide en tres apartados. El primero, plantea un marco teórico sobre cómo definir a los escuadrones de la muerte paraestatales con base en sus características y funciones como actores represivos. Durante la Guerra Fría, los regímenes autoritarios latinoamericanos diseñaron una compleja estructura represiva contrainsurgente, la cual involucró a diversos actores y estrategias de actuación legales e ilegales en la contención y eliminación de las disidencias al orden hegemónico. A partir de esta premisa, el apartado analiza la especificidad del papel jugado por los escuadrones dentro del fenómeno de la represión y que, a su vez, los distinguieron de otros actores como los militares o los paramilitares. El resultado de estas reflexiones consiste en la definición de los escuadrones de la muerte paraestatales como cuerpos represivos de origen clandestino que se conformaron principalmente con efectivos y recursos del Estado y las fuerzas de seguridad, los cuales ejercieron una violencia ilegal y selectiva contra las disidencias político-sociales urbanas que no eran partícipes directas de la lucha armada. En cuanto a sus estrategias de actuación, los escuadrones practicaron brutales ejecuciones extrajudiciales, algunas precedidas del secuestro y tortura de la víctima, visibilizadas públicamente para aterrorizar a la sociedad y disuadir la movilización popular y contestataria.

El segundo apartado aterriza en el contexto histórico que posibilitó la aparición de los escuadrones de la muerte paraestatales bajo la presidencia de Julio César Méndez Montenegro (1966-1970), centrando la atención en la gestación del complejo contrainsurgente de la época y la distribución de tareas, escenarios y sujetos a reprimir por los actores que lo conformaron, incluidos los escuadrones. En el tercer apartado, se traza la historia represiva de la NOA, atendiendo su composición social y los mecanismos de actuación que confirman su caracterización como escuadrones de la muerte paraestatales, así como sus principales objetivos, víctimas y las repercusiones político-sociales de sus crímenes. Por último, en la conclusión se presenta una síntesis de los argumentos expuestos a lo largo del artículo.

\section{Los escuadrones de la muerte paraestatales. Definición de un actor represivo}

La represión es el acto mediante el cual los Estados modernos buscan contener y eliminar potenciales amenazas al orden hegemónico. Formalmente, el ejercicio de la coerción recae en los instrumentos legales y en las fuerzas de seguridad tradicionales de un Estado como los militares y las policías. Sin embargo, ante situaciones de gran efervescencia político-social o que son percibidas como tales, existe la posibilidad de que la represión opere a través 
de un amplio conjunto de actores, no vinculados estrictamente al Estado, pero cuyos intereses comulgan con sus preceptos de orden y estabilidad. Cuando ello ocurre, estamos ante un complejo contrainsurgente: la ordenación del poder contra fenómenos de insurrección en los que se articulan múltiples estructuras y estrategias de actuación, que exceden el ámbito de lo propiamente militar, con el doble objetivo de preservar la identidad del aparato estatal en relación con la naturaleza del régimen y asegurar su continuidad hegemónica (Franco, 2002, p. 59).

La idea del complejo contrainsurgente permite entender al fenómeno de la represión como un proyecto de disciplinamiento social donde actores de distinto origen y procedencia se articulan en sus acciones violentas contra las amenazas al orden y a quienes detentan el poder estatal. Además, posee dos implicaciones de suma relevancia. La primera es la descentralización de la represión, ya que desde el Estado se puede propiciar la aparición de organizaciones represivas al margen de la ley como confiar a actores civiles la preservación de sus intereses y que, mientras se cumpla esta norma, no representan una pérdida real del monopolio de la violencia, aunque siempre está latente dicha posibilidad (Franco, 2002, p. 70). La segunda es la existencia de una estructura dual de la represión, donde conviven mecanismos legales e ilegales de coerción, propia de regímenes cuya prioridad no es velar por el estado de derecho sino procurar la "seguridad nacional", entendida como la preservación del status quo y los intereses de los detentores del aparato estatal y sus aliados en nombre del bienestar supremo de la nación ante fenómenos de insurrección².

La estructura legal de la represión está constituida por las acciones coactivas que los Estados modernos ponen en práctica con base en sus normas jurídicas. La invocación de la ley y el derecho busca dotar de legitimidad al ejercicio de la coerción e, incluso, justificar los excesos de las autoridades en nombre de la estabilidad del pacto social; apelaciones que, contradictoriamente, han fomentado las insurrecciones en América Latina y la invocación de estas al derecho de rebelión contra el uso arbitrario de poder por parte de gobiernos y gendarmes, cuyos abusos los colocan al margen de la ley (Sosa, 1997, pp. 23-25).

A pesar de lo anterior, el aparato estatal recurre a diversas estrategias represivas que están contempladas en sus normativas legales para mostrarse garante de la armonía ciudadana, entre ellas, el uso de las fuerzas de seguridad

2 El estado de derecho es un modelo organizativo de la sociedad donde toda acción está sujeta a normas jurídicas de conocimiento público, regulación que busca el respeto a la integridad humana como al orden público. En contraste, los Estados de seguridad nacional se caracterizan por regular las relaciones sociales a partir de la idea de la amenaza o conflicto permanente, lo que se traduce en una fase de alerta general contra los enemigos a los intereses de la nación, que pueden ser externos como internos; estos últimos ya no considerados ciudadanos sino disidentes contrarios al orden y que deben ser eliminados al no adherirse a los valores y principios nacionales (Rivas Nieto y Rey García, 2009, p. 172). 
tradicionales en la salvaguarda del orden dominante, el sistema penal, la asignación de funciones contraguerrilleras a unidades militares/policiales, los acuerdos de asistencia militar externa directa o indirecta y el estado de excepción; al que se recurre en situaciones de extrema convulsión social y que consiste en la suspensión de las garantías constitucionales y del ordenamiento vigente para asegurar la existencia del mismo una vez superada la crisis ${ }^{3}$.

La represión ilegal, por su parte, es la coerción que se sobrepone a todo constreñimiento de orden jurídico-legal como moral y socialmente aceptable, lo que garantiza la eficacia política de la dominación mediante el uso arbitrario y excesivo de la fuerza (Franco Restrepo, 2009, p. 253). Debido a que el aparato estatal y las fuerzas de seguridad pretenden mantener su accionar en los parámetros de lo legal, para así sostener el aura de legitimidad ante la sociedad, este tipo de represión la practican en la clandestinidad o la delegan en fuerzas irregulares, que mantienen una relación ambigua con quienes ejercen el poder del Estado, como en actores no estatales. Entre los primeros pueden mencionarse a las organizaciones paramilitares y los escuadrones de la muerte; mientras los segundos están representados por organizaciones civiles de ideología anticomunista y el mercenarismo corporativo ${ }^{4}$.

Bajo el esquema de la estructura dual de la represión, podemos ubicar a los escuadrones de la muerte como fuerzas represivas que operan al margen de la ley. Su estructura organizativa es informal y clandestina, con la intención de proteger la identidad de sus miembros durante el ejercicio de sus operativos. Esta es la principal diferencia que tienen los escuadrones respecto

3 Para Giorgio Agamben (2014) no existe contradicción alguna en la manera en que opera la lógica del estado de excepción, siendo el mecanismo que permite la reproducción de las relaciones de dominación según las normas establecidas por el aparato estatal: "Lejos de responder a una laguna normativa, el estado de excepción se presenta como la apertura en el ordenamiento de una laguna ficticia con el objetivo de salvaguardar la existencia de la norma y su aplicabilidad a la situación normal. ... Es como si el derecho contuviese una fractura esencial que se sitúa entre la posición de la norma y su aplicación y que, en el caso extremo, puede ser colmada solamente a través del estado de excepción, esto es, creando una zona en la cual la aplicación es suspendida pero la ley permanece, como tal, en vigor" (p. 72).

4 El mercenarismo corporativo está conformado por organizaciones financiadas con capital privado de gremios empresariales nacionales o transnacionales y constituidas en su mayoría por trabajadores que se encargan de reprimir a sus pares o a todo sector social que amenaza los intereses de las élites político-económicas. En América Latina, el mercenarismo corporativo es claramente perceptible en el caso de Colombia. A lo largo del conflicto armado colombiano, los sectores con gran capital económico, principalmente ganaderos, terratenientes, esmeralderos, narcotraficantes y compañías transnacionales como Chiquita Brands, crearon cuerpos de seguridad privados para proteger sus propiedades de las guerrillas y para expandirlas territorialmente a través del despojo violento de tierras a campesinos e indígenas, perpetuando con ello el ciclo de acumulación del capital. Si bien este fenómeno represivo es constatable desde la década de 1960, adquirió notoriedad en la década de 1980 debido a dos condicionantes que marcaron una escalada en la violencia: la aparición de las llamadas autodefensas, buena parte de ellas constituidas por cuerpos mercenarios, que dieron germen a las organizaciones paramilitares contemporáneas como las Autodefensas Campesinas de Córdoba y Urabá (ACCU) de la familia Castaño Gil; y la emergencia del narcotráfico, cuyos líderes se convirtieron en empresarios a través de la compra de tierras en zonas controladas por la guerrilla, a las cuales expulsaron y presionaron con la contratación o creación de grupos paramilitares, siendo el primero de ellos el Muerte A Secuestradores (MAS), creado en respuesta al secuestro de la hija de uno de los capos del Cártel de Medellín por el Movimiento 19 de Abril (M-19) (Reyes Posada, 2007, p. 357). 
a las organizaciones paramilitares, cuya estructura organizativa y sedes de operación son ampliamente conocidas por la población sobre la que se ejerce la represión, llegando incluso sus miembros a operar con uniforme, tal como lo muestran las autodefensas colombianas y, en menor medida, las Patrullas de Autodefensa Civil (PAC) que actuaron en Guatemala durante los últimos años del conflicto armado interno (1981-1996).

La composición social de los escuadrones revela su estrecha vinculación con las fuerzas represivas estatales, al estar integrados en su mayoría por policías o militares en actividad, aunque también existe colaboración de gendarmes retirados y civiles en tareas de inteligencia y delación. Por esta razón, considero adecuado añadir el término "paraestatal" al concepto de escuadrones de la muerte, entendiendo la paraestatalidad como una política de Estado, resultante de la descentralización de la represión, donde efectivos y recursos estatales son utilizados para el ejercicio de una violencia ilegal y clandestina útil a la contención de toda disidencia.

Los escuadrones de la muerte paraestatales surgieron como parte integral de los planes de contrainsurgencia ideados al calor de la Guerra Fría y la descolonización del Tercer Mundo. La contrainsurgencia se diseñó como una estrategia capaz de hacerle frente a la nueva modalidad de guerra que propusieron los movimientos de liberación nacional, donde los ataques sorpresa de las guerrillas y su asimilación dentro de la población civil volvieron inútiles a las tácticas militares convencionales. Como respuesta, la contrainsurgencia propuso un nuevo esquema de represión donde, a la tarea de ubicar y destruir los grupos armados contrahegemónicos, se le sumaron la "acción psicológica" o "acción cívica”, entendida como campañas de propaganda y trabajo social que ganaran "las mentes y los corazones" de la población; el control de los civiles para eliminar la potencial base social de las guerrillas; y el uso de métodos violatorios de los derechos humanos como la tortura y la propagación del terror para disuadir cualquier fenómeno revolucionario mediante la creación o fomento de fuerzas irregulares e ilegales como los grupos paramilitares y los escuadrones.

Un manual en estrategia contrainsurgente, redactado en Estados Unidos en la década de 1960, muestra cómo el objetivo central de los cuerpos represivos ilegales, "semimilitares", en el documento, no es el enfrentamiento contra la guerrilla, sino el control coercitivo de la población con el fin de romper los lazos con sus potenciales bases de apoyo y simpatizantes. El manual señala que dicho control se logrará al "cortar las relaciones de apoyo" entre la población y los guerrilleros, "descubrir y neutralizar la organización y las actividades insurgentes en la comunidad" y "proporcionar a la población un ambiente seguro en lo físico y en lo psicológico", entendiendo la seguridad como el ordenamiento social al status quo, erradicando lo disidente. Dichas tareas serán compartidas con la policía, mientras que los militares colaborarán "como fuerza de respaldo y como fuente de especialistas", lo que muestra la estrecha 
relación de la estructura dual de la represión del complejo contrainsurgente. Por último, las acciones "semimilitares" son entendidas como operaciones de "purificación política", eufemismo que implícitamente reconoce el necesario sacrificio de la vida humana en la preservación del orden y el fin de lo insurgente (Escuela de Guerra Especial del Ejército de los Estados Unidos, 1968, pp. 4/43-4/44).

Partiendo de la lógica contrainsurgente, los escuadrones no son una fuerza de combate, sino grupos especializados en tareas de vigilancia y aniquilación de los sectores de la población señalados de colaboradores o simpatizantes de la guerrilla. No era del todo necesario comprobar tal vínculo, pues el hecho de incurrir en cualquier acto de oposición al régimen político convirtió a los disidentes en sospechosos promotores de la insurgencia o "subversión" y, por tanto, en acreedores de la represión. En consecuencia y trasladándolo a la historia de América Latina durante la Guerra Fría, la gran mayoría de las víctimas de los escuadrones no fueron guerrilleros, sino personas cuyo activismo político-social fue interpretado como prueba irrefutable de la existencia de un proceso insurreccional en ciernes y que atentaba contra la nación o un sistema político.

La idea de una potencial amenaza contra la estabilidad y el orden convirtió a los escuadrones, gracias a su condición paraestatal, en instrumentos de defensa de la seguridad nacional por parte de los regímenes autoritarios latinoamericanos. En el contexto de la Guerra Fría, los teóricos y practicantes de la seguridad nacional en América Latina se alinearon ideológicamente a la cruzada mundial contra el comunismo, percibido como un movimiento conspirativo que buscó destruir a las naciones libres, cristianas y civilizadas de Occidente por medio de los movimientos guerrilleros, los partidos considerados de izquierda (aún sin ser comunistas) y, en general, cualquier fenómeno crítico y contestatario (Rivas Nieto y Rey García, 2009, p. 163). En otras palabras, el anticomunismo se convirtió en el marco ideológico que guió la política de seguridad nacional de la época bajo la premisa de combatir el mal de la subversión marxista, instigadora del terror político y la anomia social.

El anticomunismo profesado por los escuadrones fue de "matriz" nacionalista, la cual postuló la idea de que la nación, ente orgánico y armónico de las individualidades, se encontraba en decadencia y/o peligro por la amenaza comunista, una fuerza disgregadora de los valores espirituales y culturales que, además, tendía a impulsar el conflicto social. En ese sentido, el comunismo se presentó como una ideología foránea proclive a la destrucción del orden en el que la nación sustenta su existencia, convirtiendo a los acusados de comunistas en "enemigos internos", traidores y apátridas por servir a intereses extranjeros que atentaban contra la unidad de la "comunidad imaginada" (Casals A., 2013, pp. 37-38). 
Con base en la definición anterior, podemos argumentar que los escuadrones concibieron su existencia y sus acciones como salvaguardas de la integridad de la nación, de la defensa de la seguridad nacional frente a los "comunistas", otredad negativa que se corporizó en las disidencias a los regímenes en turno y que, más allá de que fueran efectivamente comunistas, o no, eran merecedoras de la violencia e incluso la muerte por simbolizar la antítesis de lo nacional. Basta con revisar los nombres y lemas de los escuadrones latinoamericanos para constatar el imaginario anticomunista de "matriz" nacionalista que profesaron. Por ejemplo, la Alianza Anticomunista Argentina (Triple A), el principal escuadrón que operó en la nación sudamericana durante el peronismo de los setenta (1973-1976), llevó por nombre una insignia de identidad que apeló a la unión de los "verdaderos" argentinos en contra de los "enemigos" de la nación y del régimen peronista; mientras que los diversos escuadrones que operaron durante la guerra civil en El Salvador (1979-1992) tuvieron como lema recurrente el "haga patria, mate un subversivo", síntesis de una cosmovisión donde la muerte del "enemigo" redimía los agravios causados a una nación en conflicto.

Los escuadrones se distinguieron del resto de los actores represivos del complejo contrainsurgente por la forma en cómo procedieron a la eliminación física de los "enemigos". Al ser cuerpos que operaban desde la clandestinidad, los asesinatos que protagonizaron eran selectivos, eligiendo víctimas reconocibles por su trayectoria en organizaciones o movimientos críticos al orden hegemónico: intelectuales, líderes sindicales y estudiantiles, defensores de presos políticos, miembros del progresismo católico, entre otros. El objetivo de estos crímenes era instaurar un clima de terror disciplinador que disuadiera la protesta y la movilización popular. Por eso, la víctima era brutalmente torturada antes de ser asesinada, cuyo cuerpo era expuesto en un lugar transitable para su fácil ubicación y visibilidad pública, dejando prácticas de lesa humanidad como la desaparición forzada en manos de otros agentes represivos. Como señala Ignacio Cano (2001), para los escuadrones "el anonimato debía corresponder a los autores pero no a las víctimas, que debían ser encontradas para escarmiento y ejemplo general” (p. 226).

Los crímenes de los escuadrones pueden interpretarse como prácticas de limpieza político-social y como actos de terror propagandístico. La noción de limpieza se edificó como un precepto ideológico útil a los fenómenos de represión modernos, al justificar el fin de la vida a partir de categorías deshumanizantes de sentido higienista o biologicista, que fundamentaron el aniquilamiento del "otro", percibido como un "agente infeccioso", en aras de la preservación de la vida del colectivo social (Feierstein, 2007, p. 118). La limpieza como discurso y praxis reconfigura las relaciones sociales, mediante la labor de sanar los tejidos enfermos. Así, la limpieza de los sujetos sucios e indeseables busca no solo la destrucción del "mal", el germen objetivado en sujetos que afectan la normatividad, también pretende que la curación sea 
instrumental al disciplinamiento social, atravesado por la imposición de la cosmovisión del represor a sus víctimas y al resto del cuerpo social.

Las acciones de los escuadrones fueron prácticas de limpieza político-social porque buscaron la destrucción del "enemigo", cuya disidencia dañaba la normalidad de un sistema político o de una nación entera. La "purificación" se dio en dos terrenos interconectados. Uno simbólico, donde palabras como "comunistas", "subversivos", "marxistas", "infiltrados" o "traidores", presentes en los manifiestos y amenazas de los escuadrones, buscaron denigrar a las víctimas para legitimar su muerte por el bien del colectivo mayor; el otro material, la concreción del asesinato, donde la vejación y humillación de los cuerpos de las víctimas buscó la destrucción física como moral del enemigo ideológico, una purificación social lograda, irónicamente, con el ensuciamiento corpóreo de la víctima. De ahí la racionalidad detrás del impacto emocional que causaron la crueldad de los escuadrones, pues el fin último de la violación al cuerpo humano es visibilizar el terror para inculcar miedo y disciplina en la sociedad.

Paralelamente, la "limpieza" de los escuadrones es un acto de propaganda. El dramático ritual de degradación de la vida y el cuerpo humano presente en sus crímenes es propagandístico en sí mismo al establecer una comunicación directa y cruda con los receptores, al alertarles de los riesgos de formar parte o simpatizar con los disidentes. Por su parte, los mensajes reivindicativos sirvieron como propaganda al difundir la justificación de sus actos, reafirmando su intencionalidad al explicar por qué la víctima fue objeto de la agresión y por qué merecía morir. Las repercusiones son claras: imponer y mantener vivo el ambiente de miedo en la sociedad, generando incertidumbre entre sus integrantes debido a la impunidad en la que se desarrollaron los crímenes y que consigue el sometimiento ante la necesidad primaria de preservar la vida. Parafraseando a Michel Foucault (2009), la acción propagandística de los escuadrones funcionó como un dispositivo de control que logró la interiorización de la represión, asegurando así el triunfo del disciplinamiento al tornarse los sujetos en "cuerpos dóciles" a merced de la voluntad de quienes ostentaron el poder estatal (p. 233).

Las acciones de los escuadrones se limitaron a los espacios urbanos, llegando rara vez a actuar en comunidades rurales. Esta afirmación se desprende de las siguientes consideraciones: 1) la importancia de la ciudad para la insurgencia armada según la lógica contrainsurgente, al ser el espacio donde podía obtener apoyo financiero y reclutar a los simpatizantes; 2) la represión en las zonas rurales fue protagonizada por fuerzas estatales en colaboración con grupos paramilitares, estos últimos integrados por miembros de las comunidades debido a sus conocimientos del terreno geográfico y de los habitantes, labor de inteligencia eficaz para informar a los aparatos de Estado de los movimientos de la guerrilla en la zona y para la socialización del miedo al indicar objetivos preferenciales de la represión 
(Cano, 2001, pp. 223-224); 3) los crímenes de los escuadrones, tanto los reconocidos públicamente como los dilucidados por investigaciones judiciales y periodísticas, remiten a las ciudades como su epicentro ${ }^{5}$.

Los escuadrones, como estrategia contrainsurgente, tienden a desaparecer una vez que la amenaza al orden hegemónico es contenida, o bien, por los cambios del sistema político que conducen a la recentralización de la represión por el estamento castrense y policial, tal como ocurrió en las dictaduras militares del Cono Sur de la década de 1970, particularmente Chile y Argentina, donde las fuerzas estatales tuvieron el protagonismo indiscutible del monopolio de la violencia. Sin embargo, la reconfiguración del contexto político y del complejo contrainsurgente no implica necesariamente el fin de los escuadrones, ya que estos pueden subsistir mediante un cambio de enfoque en los sujetos a reprimir, transitando del disidente político al delincuente común e, inclusive, convirtiéndose en organizaciones criminales como ocurrió en El Salvador de la posguerra6.

En síntesis, los escuadrones de la muerte paraestatales que operaron en América Latina, en el contexto de la Guerra Fría, pueden definirse como organizaciones represivas constituidas clandestinamente con efectivos y recursos del Estado para ejecutar una violencia ilegal que se evidenció en los crímenes más crueles y su visibilidad pública y propagandística para instaurar un clima de terror y miedo en la sociedad que buscó disuadir cualquier comportamiento o actitud disidente al orden estatal. Como parte integral de un complejo contrainsurgente, las funciones represivas de los escuadrones se limitaron a espacios urbanos y a la selección de víctimas concretas y reconocibles por su aparente simpatía con las guerrillas, pero sobre todo por su trayectoria políticosocial crítica al régimen operante. En ese sentido, los escuadrones fueron un dispositivo de control poblacional que pretendió eliminar la potencial base social de la guerrilla y a todo movimiento contestatario presente en las ciudades; sujetos sociales devenidos, según el imaginario del anticomunismo nacionalista que profesaron los escuadrones, en enemigos de la nación por buscar destruir sus cimientos y el bienestar de sus habitantes.

5 Tomemos a la Alianza Anticomunista Americana (Triple A) de Colombia como caso ilustrativo. La Triple A colombiana (1978-1980), constituida por personal militar del Batallón de Inteligencia y Contrainteligencia Charry Solano (BINCI), operó en Bogotá, como lo constatan sus principales acciones: pintas de muros, amenazas a defensores de los presos políticos, atentados a las sedes locales del Partido Comunista y de prensa crítica al gobierno y las ejecuciones reivindicadas, siendo la primera la del abogado Manuel Martínez Quiroz, otrora fundador del Ejército de Liberación Nacional (ELN), cuyo cadáver fue encontrado en un basurero de la ciudad con notorias huellas de tortura (Calvo Ospina, 2008, p. 135).

6 El fin de la guerra civil salvadoreña y el tránsito a la normalidad democrática en la década de 1990 no significó el cumplimiento pleno de la reinserción de los excombatientes a la vida civil, quienes formaron bandas armadas y delictivas para su sostén económico. Esta situación es notoria en los escuadrones de la muerte que, debido a su informalidad y clandestinidad, no fueron objeto de la desmovilización, incursionando en la delincuencia común y practicando limpieza social contra otros delincuentes y ajusticiamientos motivados por la venganza personal. Aunque abandonaron en apariencia la motivación política, sus asesinatos mantuvieron la brutalidad de antaño, recuerdo del horror del pasado reciente en el país centroamericano (Garzón Rivera, 2016, pp. 162-163). 


\section{El complejo contrainsurgente y los escuadrones de la muerte durante el gobierno de Méndez Montenegro (1966-1970)}

De acuerdo con la Comisión para el Esclarecimiento Histórico de Guatemala (1999, T. I, p. 281), existieron 35 organizaciones anticomunistas que operaron como escuadrones de la muerte a lo largo de las cuatro décadas que duró el conflicto armado interno, teniendo su mayor auge bajo el gobierno civil de Julio César Méndez Montenegro (1966-1970) con un aproximado de 20. Si bien son necesarias futuras investigaciones que atiendan con detenimiento cuáles de estas organizaciones fueron solo nombres de fachada para encubrir las acciones de los escuadrones realmente existentes, el índice cuantitativo revela la importancia que adquirieron estos actores represivos a finales de la década de 1960, resultado de un contexto histórico particular donde el fortalecimiento de las guerrillas, aunado al descrédito de los militares en el poder, condicionaron no solo la llegada de un civil a la presidencia sino también la aparición de un complejo contrainsurgente en el que los escuadrones tuvieron un destacado papel.

Durante el gobierno militar del coronel Enrique Peralta Azurdia (19631966), los grupos guerrilleros del Movimiento Revolucionario 13 de Noviembre (MR-13) y de las Fuerzas Armadas Rebeldes (FAR), lograron asentarse en la Sierra de las Minas, al nororiente de Guatemala, aprovechando la escasa profesionalidad militar en materia contrainsurgente. Por su parte, y pese a la cerrazón del juego institucional y a los constantes estados de sitio, en las ciudades existieron diversos focos contestatarios al régimen, representados principalmente por el Partido Guatemalteco del Trabajo (PGT), de orientación comunista y del cual las FAR fueron su "brazo militar" durante la década de 1960, organizaciones estudiantiles de la Universidad de San Carlos (USAC) y sindicatos que abogaban por una mejora en la calidad de vida de los trabajadores. Si bien estas fuerzas no constituían una amenaza seria al régimen, el temor de los militares a que fueran cooptadas por los comunistas del PGT y constituyeran un frente amplio que los llevara al poder coadyuvó a que se convocaran elecciones presidenciales para el 6 de marzo de 1966 (Sabino, 2008, T. II, p. 31).

Los cercanos a Peralta Azurdia constituyeron su propio partido, Partido Institucional Democrático (PID), con el fin de legitimar y perpetuar la estadía de los militares en el poder por la vía electoral. Los otros partidos contendientes eran el Movimiento de Liberación Nacional (MLN), que aglutinaba a los viejos partidarios de la contrarrevolución que derrocó a Jacobo Arbenz en 1954, y el Partido Revolucionario (PR), que pretendía recuperar las banderas de justicia social de la revolución de 1944 bajo el liderazgo de Mario Méndez Montenegro. Rumbo a la contienda, sin embargo, acontecieron dos hechos que contribuyeron a la derrota y desprestigio de los militares. El primero fue la muerte, 
en la versión oficial suicidio, del candidato del PR el 31 de octubre de 1965, hecho que conmocionó a la opinión pública y provocó la designación de su hermano Julio César como su sucesor, quien aprovechó el descontento como capital político. El otro acontecimiento fue el caso de "los 28", el primer acto de desaparición forzada masiva en Guatemala7, ocurrido días antes de las elecciones y que volcó a todas las fuerzas partidistas opositoras, exceptuando el MLN, a votar por el PR. En consecuencia, el triunfo de Méndez Montenegro fue resultado del voto de castigo a la represión militar, avivando a su vez la esperanza del retorno a la normalidad institucional.

Sin embargo, tal aspiración se truncó rápidamente. Los militares forzaron a Méndez Montenegro a firmar un "pacto secreto" que condicionó su ascenso a la presidencia. En él, se estipuló que las Fuerzas Armadas no atentarían contra el nuevo gobierno si mantenía la represión y proscripción de todas las actividades consideradas comunistas, el apoyo al Ejército en la guerra sin cuartel contra las guerrillas, el respeto a la autonomía castrense y a la amnistía, emitida por el gobierno saliente, que garantizaba la impunidad de los crímenes cometidos por las fuerzas estatales en la represión a la subversión (en alusión implícita al caso de "los 28"). En otras palabras, si bien Méndez Montenegro asumió la presidencia, el control fáctico del poder y del Estado siguió en manos militares, prevaleciendo la defensa de la "seguridad nacional" sobre el estado de derecho.

Para mantener la fachada de apego al orden institucional por parte de los militares, el nuevo régimen permitió la descentralización de las tareas represivas que condujo a la aparición de un complejo contrainsurgente y a la estructura dual legal/ilegal de la represión. El Ejército limitó sus tareas formales al combate guerrillero y a operaciones de "acción cívica" en el campo, a la par que vivió un proceso de profesionalización en contrainsurgencia gracias a la asistencia militar estadounidense, que incluyó el uso de técnicas propias de la Guerra de Vietnam como el lanzamiento del napalm sobre los focos guerrilleros (Jonas, 1979, p. 202). Las zonas rurales con presencia guerrillera se reorganizaron con el establecimiento de "comisionados militares", civiles que habían hecho su servicio militar y en torno a los cuales se constituyeron los grupos paramilitares que vigilaban a los miembros de su propia comunidad. Además, el gobierno legalizó el mercenarismo corporativo al permitir que finqueros y terratenientes organizaran cuerpos de seguridad privados para

7 Entre el 3 y el 5 de marzo de 1966, un comando del Ejército secuestró a una treintena de personas, todas ellas vinculadas a la dirigencia del PGT y entre quienes se encontraban Víctor Manuel Gutiérrez y Leonardo Castillo Flores, líderes de la rama sindical y campesina del partido respectivamente. Su paradero se desconoció durante meses, hasta que investigaciones no oficiales descubrieron que las víctimas fueron torturadas y asesinadas, siendo sus cuerpos lanzados al mar por la Fuerza Aérea Guatemalteca (Cáceres, 1980, p. 24).

8 El pacto íntegro fue revelado en 1973 por el periodista Clemente Marroquín, vicepresidente de la república con Méndez Montenegro, en el diario La Hora. Para una versión completa del documento véase Villagrán Kramer (2009, pp. 365-369). 
proteger sus propiedades, teniendo la facultad de arrestar y disparar contra guerrilleros y campesinos que atentaran en su contra ${ }^{9}$; atribución extendida a multinacionales como la United Fruit Company (Melville \& Melville, 1971, p. 223). El éxito de las tareas represivas de estos actores residió en la casi total erradicación del MR-13 y las FAR, en 1967. En un repliegue estratégico, los residuos de las guerrillas se trasladaron a las ciudades, principalmente a la capital guatemalteca, para proseguir la lucha armada y reestructurar sus bases de apoyo.

Es en este cambio de escenario del conflicto armado donde residió la emergencia de los escuadrones de la muerte paraestatales de la época. Para contener definitivamente a la guerrilla, era necesario un actor que eliminara su potencial base de apoyo urbana sin involucrar directamente a las fuerzas estatales. Por esta razón, se constituyeron en la clandestinidad con miembros de la Inteligencia del Ejército, policías militarizadas, miembros del MLN e, inclusive, con ex guerrilleros (Comisión para el Esclarecimiento Histórico, 1999, T. II, p. 115). Los escuadrones más significativos del momento fueron, junto a la Nueva Organización Anticomunista (NOA), el Movimiento de Acción Nacionalista Organizado (MANO), conocido popularmente como la Mano Blanca y el Ojo por Ojo.

La Mano Blanca, así nombrada por la mano color blanco sobre un fondo rojo que apareció en sus panfletos y listas de muerte, fue el escuadrón con mayor operatividad entre junio de 1966 y abril de 1968. Originalmente nació como una organización civil violenta al amparo del MLN, siendo copada por las fuerzas estatales que la convirtieron en escuadrón. Su sede de operaciones se encontraba en el IV Cuerpo de la Policía Nacional, ciudad de Guatemala; además de recibir órdenes directas del coronel Rafael Arriaga Bosque, ministro de Defensa de Méndez Montenegro. Su principal líder fue Raúl Lorenzana, comerciante de estrechos vínculos con el estamento castrense desde su participación en el derrocamiento de Jacobo Árbenz. La Mano operó en la capital guatemalteca y en varias localidades al nororiente del país, entre ellas Los Amates, Río Hondo, Chiquimula y Zacapa. Una de sus mayores acciones fue el secuestro del arzobispo Mario Casariego en marzo de 1968. En respuesta, el presidente destituyó de sus cargos a Arriaga Bosque y a otros jefes militares vinculados a la Mano, mientras Lorenzana murió asesinado un mes después. Tras su descabezamiento desapareció de la escena política, aunque su nombre se utilizó en varias ejecuciones cometidas en la década de 1970 (Comité de Defensa de los Derechos Humanos,

$9 \quad$ La legalización de estos cuerpos de seguridad se estableció mediante una reforma al artículo 154 del Código Penal en diciembre de 1966, que planteó lo siguiente: "A todo propietario de finca rústica, sus administradores o representantes legales, se les equipara a la categoría de agentes de autoridad y están obligados a capturar, o en su caso a perseguir, a toda clase de delincuentes, poniéndolos a la disposición de la autoridad más inmediata" (Pueden portar armas Finqueros..., 7 de diciembre de 1966, p. 40). 
1969, pp. 45-46; Aguilera Peralta, Romero Imery \& Torres-Rivas, 1981, pp. 134 y 136).

Por su parte, el Ojo por Ojo fue un escuadrón constituido por efectivos del Ejército que operó durante el primer semestre de 1970, a raíz del secuestro y asesinato del embajador alemán Karl von Spreti a manos de las FAR, en marzo de aquel año. Lo anterior explica que sus principales objetivos políticos fueran los simpatizantes de las FAR y los militantes del PGT, si bien también extendieron constantes amenazas a la USAC. Entre sus crímenes conocidos se encuentra la ejecución de César Montenegro Paniagua, exdiputado del PGT y primo del presidente, ocurrido en la ciudad de Guatemala el 4 de abril de 1970 (Aguilera Peralta, 1971, p. 4/16).

Ideológicamente, los escuadrones guatemaltecos se adscribieron al anticomunismo nacionalista, planteando que los críticos al sistema eran "enemigos" al servicio del comunismo internacional y cuya muerte era necesaria para la "purificación política" de la unidad nacional. Por ejemplo, en un volante del Consejo Anticomunista de Guatemala $(\mathrm{CADEG})^{10}$ se lee la siguiente amenaza:

Agrupaciones anticomunistas de Guatemala y los pelotones de ajusticiamiento diseminados en todo el país: deben buscar hasta encontrar donde se hallen tamaños traidores castro-comunistas quienes deben pagar con su vida y el crimen de lesa patria cometido al pretender regresar al país, y sin piedad alguna deben morir como perros rabiosos y sus inmundos cadáveres no deben ser cobijados por la tierra bendita de Guatemala, sino que deben servir para hartazgo de las aves de rapiña (Consejo Anticomunista de Guatemala, s. f., citado por Aguilera Peralta et al., 1981, p. 127).

Guiados por este imaginario anticomunista, los escuadrones guatemaltecos dirigieron sus acciones contra individuos acusados de promover "el mal" del comunismo, principalmente colaboradores o supuestos simpatizantes de la guerrilla, miembros del PGT, dirigentes de los sindicatos autónomos a la burocracia estatal ${ }^{11}$, personal docente de la USAC y estudiantes de la Aso-

10 El CADEG apareció entre 1967 y 1968 en la ciudad de Guatemala. Sus manifiestos se caracterizaron por una constante apelación a la unidad, tanto organizativa como programática, de las organizaciones anticomunistas de la época. Sin embargo, la ausencia de información sobre sus integrantes y acciones hace sospechar que el CADEG fue un escuadrón "fantasma" que sirvió de cobertura a los realmente existentes como la Mano Blanca y la NOA, aumentando la incertidumbre social sobre la autoría de los crímenes (Comisión para el Esclarecimiento Histórico, 1999, T. II, p. 112).

11 El sindicalismo autónomo se opuso constantemente a las legislaciones emanadas de los gobiernos de la contrarrevolución que restringían los derechos de los trabajadores, entre ellos el de la huelga, cuyo permiso y legitimidad dependía de un reconocimiento previo por los tribunales de justicia. Para el periodo de gobierno de Méndez Montenegro, la mayoría de los sindicatos de esta corriente se adscribieron políticamente a la socialdemocracia. Entre las principales organizaciones, cuyos miembros fueron víctimas de los escuadrones, se encuentran la Federación Autónoma Sindical de Guatemala (FASGUA), la Confederación Sindical de Guatemala (CONSIGUA), la Confederación de Trabajadores de Guatemala (CONTRAGUA), el Sindicato de Acción y Mejoramiento Ferrocarrilero (SAMF), la Central Sindical de Guatemala (CSG) y el Movimiento Campesino Independiente (MCI). Para mayor información sobre el sindicalismo autónomo entre las décadas de 1950 y 1970 véase López Larrave (1979, pp. 53-68). 
ciación de Estudiantes Universitarios (AEU), organización denunciante de la represión y los abusos militares. Su terror buscó el disciplinamiento de estos actores y se socializó de múltiples formas: difusión de listas de personas sindicadas de marxistas y condenadas a muerte, carteles pegados en las calles con fotografías de los condenados, cartas personales a los amenazados instigándolos a huir del país, atentados con bombas, ametrallamientos de casas, balaceras en vía pública y los asesinatos cometidos por "pelotones de fusilamiento", que arrojaban los cadáveres en lugares aledaños a las vías de entrada de las ciudades con señales de tortura (Aguilera Peralta, 1971, pp. 4/17-4/18).

En síntesis, el complejo contrainsurgente guatemalteco del gobierno de Méndez Montenegro fue resultado de la descentralización de la represión contra la disidencia político-social del entorno rural como urbano. Dicho proceso fue impulsado por el estamento militar, debido a la presión que ejerció sobre el poder civil y para dar una imagen de apego a la legalidad limitando su accionar represivo formal al combate de las guerrillas en el campo. Los escuadrones de la época surgieron de la coyuntura que significó el traslado de la lucha armada a las ciudades, enfocándose en reprimir con acciones terroristas a los disidentes que simpatizaban con la guerrilla o cuyo activismo los ubicó, en la lógica de los perpetradores, dentro del espectro del comunismo apátrida. La NOA, junto a la Mano Blanca y el Ojo por Ojo, se convirtió en uno de los actores represivos más destacados de esta tendencia.

\section{La Nueva Organización Anticomunista}

La NOA existió de marzo de 1967 a 1968, temporalidad coincidente con el traspaso de la lucha armada del campo a la ciudad. Su nombre y enunciados la adscriben al imaginario anticomunista nacionalista y a una apelación constante a la sacralización de la violencia. "Nueva Organización Anticomunista" es una insignia que apela a una tradición de la que el escuadrón se considera perteneciente, probablemente a la de la contrarrevolución iniciada en 1954, pero que necesita una renovación ante los males "comunistas" de su tiempo. Sus principales enunciados, "Por una Guatemala grande, libre y respetada" y "Comunista visto, comunista muerto", aluden a la guerra sin cuartel que la organización pretendió librar contra los sujetos a los que consideró enemigos de la nación y cuya eliminación era la única solución posible para que Guatemala recuperara su dignidad amenazada.

Gracias a la intensa labor de investigación que realizó el Comité de Defensa de los Derechos Humanos de Guatemala ${ }^{12}$ es posible identificar a los

12 El Comité de Defensa de los Derechos Humanos de Guatemala fue una entidad creada en la década de 1960 con el objetivo de denunciar ante el mundo la violencia y la represión imperante en el país centroamericano. Estuvo conformado en su mayoría por guatemaltecos exiliados en México, si bien su condición de organización anónima dificulta señalar nombres específicos de sus integrantes. En sus propias palabras, el Comité "funciona en el anonimato por razones obvias, pero 
líderes y la composición social de la NOA. De acuerdo con su informe La Violencia en Guatemala, el escuadrón estuvo conformado por militares de la sección de Inteligencia del Ejército -la G2- del cuartel militar San Rafael de Matamoros, miembros de la Policía Nacional y civiles del MLN. Su líder principal era el jefe del Servicio de Inteligencia del Ejército, coronel Máximo Zepeda Martínez (señalado como autor intelectual de la desaparición de "los $28{ }^{\prime \prime}{ }^{13}$. El segundo al mando era el civil Oliverio Castañeda Paíz, que en la década de 1970 se convirtió en uno de los principales líderes del MLN. Su centro de operaciones se encontraba en las inmediaciones del Aeropuerto de la Aurora, al sur de la ciudad de Guatemala, en una casa situada en la colonia de las Viudas de los Militares (Comité de Defensa de los Derechos Humanos, 1969, p. 44).

Al informe del Comité puede sumarse el testimonio de víctimas que, además de aportar información sobre los escuadrones de la muerte, revelan la estrecha vinculación con las fuerzas estatales en la concreción de sus operativos. De gran relevancia es el testimonio de Julio Vázquez Alvarado, estudiante de la USAC, que fue detenido por el ejército y torturado por la NOA, logrando salvar la vida por un hecho circunstancial: su amistad con Oliverio Castañeda. Vázquez Alvarado rememoró que al salir de su trabajo fue secuestrado por "individuos vestidos de civil", quienes lo llevaron a una zona donde escuchaba "el ruido de aviones que despegaban y aterrizaban", conociendo posteriormente que el sitio era "la casa de las viudas de los militares" (llamado así por la colonia donde se ubicó). Después fue trasladado a la Policía Judicial, en pleno centro de Guatemala, donde uno de sus torturadores le confesó que "el ejército les proporciona listas de gentes que deben capturar con la orden de sacarles confesión y después asesinarlos". Además, le brindó el nombre de sus jefes: Zepeda, Castañeda, los hermanos Julio y Roberto Orellana, entre otros. Al conocerse el lazo personal que unía a Vázquez Alvarado con uno de los líderes de la NOA fue puesto bajo resguardo policial y liberado días después (s. f., citado por Cáceres, 1980, pp. 120-129).

La NOA inició sus actividades terroristas difundiendo amenazas contra sus potenciales objetivos, redactadas en volantes que eran distribuidos frecuentemente por toda la ciudad de Guatemala desde aviones militares ligeros (Sharckman, 1979, p. 341). En uno de sus primeros comunicados, de marzo de 1967, el escuadrón lanzó una advertencia en apariencia dirigida a

que agrupa a destacadas e intachables personalidades de diferentes sectores de la sociedad de Guatemala", y tiene como propósito fundante dirigir las denuncias a las Asambleas Generales de las Naciones Unidas "ante la necesidad de poner en evidencia el verdadero carácter del actual gobierno guatemalteco y demandar la solidaridad de todos los pueblos del mundo" (Comité de Defensa de los Derechos Humanos, 1969, p. 6).

13 Ruano Pinzón, soldado desertor del ejército guatemalteco tras su colaboración en la desaparición de los cadáveres, testimonió a Eduardo Galeano (1967) que el coronel Zepeda mandó a fusilar a las víctimas y que él personalmente se encargó de lanzar a algunas de ellas al Océano Pacífico (pp. 60-62). 
las FAR, ya que los verdaderos destinatarios eran sus colaboradores y simpatizantes. En el mensaje se lee que

la paciencia del pueblo de Guatemala ha llegado a su término, y por cada nuevo asesinato que perpetren las FAR, ya sea en persona civil alguna, militar, religiosa, extranjera, profesional, trabajador, agricultor, industrial, comerciante, periodista, estudiante, menores de edad o alguna otra persona indefensa que resultare afectada por los asaltos a mano armada, robos, asesinatos, plagios, secuestros, etc., el CONSEJO SUPREMO de la N.O.A. ordenará la LIQUIDACIÓN FÍSICA de CINCO personas fichadas como proclives de las FAR (Nueva Organización Anticomunista, 1968a, p. 4/302).

El comunicado dejó en claro que los objetivos centrales de la violencia de la NOA no eran los guerrilleros, sino los civiles sospechosos de ayudarles en cualquier rubro. Un mes después, otro volante anunció la ejecución de Ramón Méndez Linares, Elder Amilcar Minott y Jaime de Jesús Velázquez "en cumplimiento de la promesa hecha a la ciudadanía honrada, que la N.O.A. por cada asesinato cometido por las FAR ordenaría la liquidación física de un número mayor de comunistas afiliados al Partido Guatemalteco del Trabajo" (Nueva Organización Anticomunista, 1968b, p. 4/304). Como se ilustra en la Figura 1, además de la reivindicación de la autoría del crimen se señaló la ubicación donde la población podía encontrar los cuerpos (una carretera afuera de la capital), fotografías de las víctimas torturadas y una lista de condenados a muerte, todos miembros del PGT y de la AEU. 
Figura 1. Comunicado de la NOA, reivindicando las ejecuciones de Ramón Méndez Linares, Elder Amilcar Minott y Jaime de Jesús Velázquez; y anunciando los siguientes condenados a muerte.
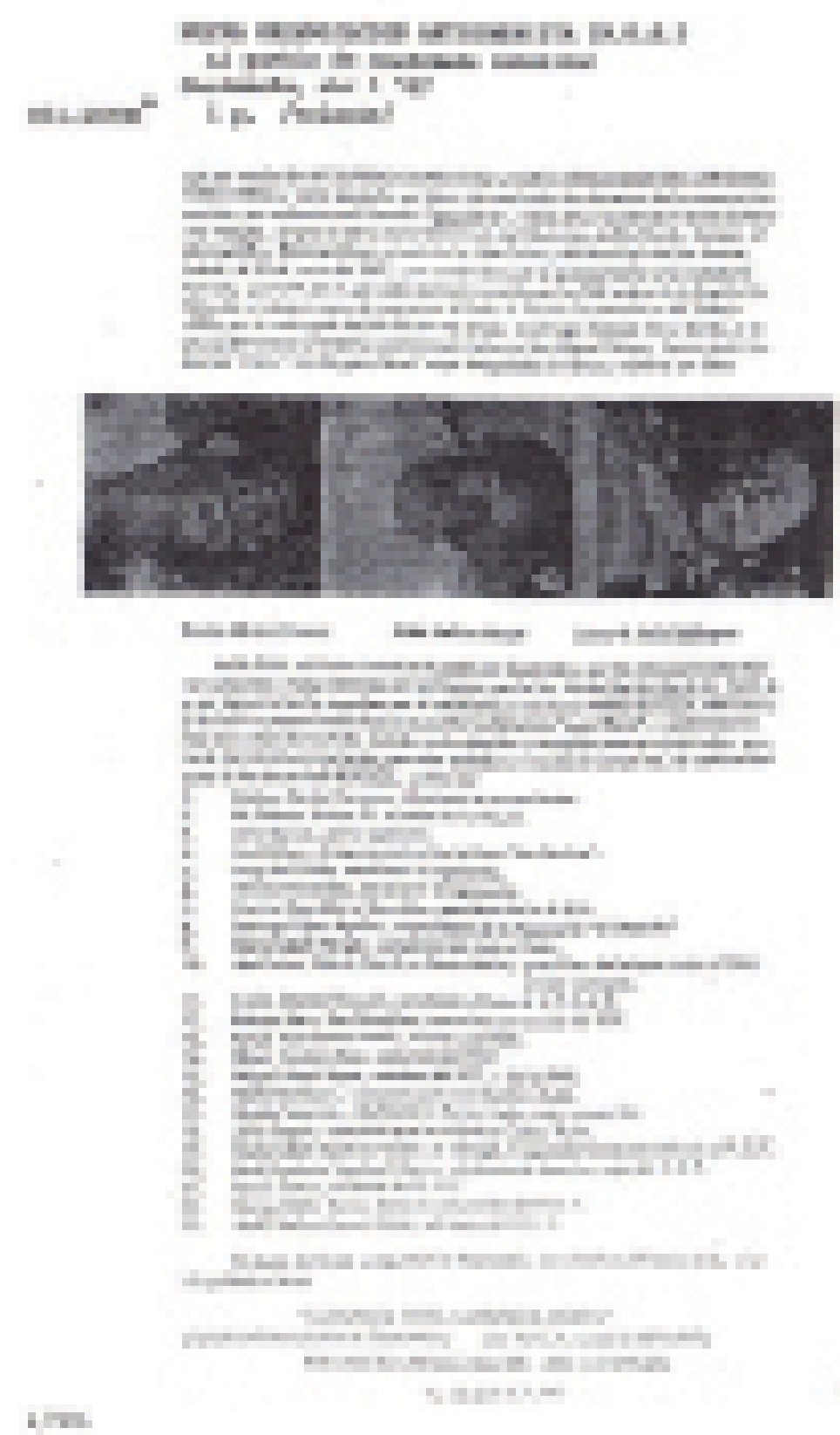

Fuente: Nueva Organización Anticomunista, 1968b, p. 4/304. 
Estos asesinatos son un claro ejemplo de la propaganda contrainsurgente de la NOA y su interpretación como un acto de limpieza. Se justifica el asesinato como parte de un enfrentamiento contra los que atentan "la paz y la seguridad" de Guatemala, indicando el sitio del crimen para que la sociedad lo constate y así cumpla su rol de terror disciplinador. Las imágenes refuerzan el dispositivo de control al mostrar los cadáveres torturados de manera explícita (al de Velázquez se le introdujeron alfileres en las pupilas), una brutal advertencia del destino que le esperaba a todos los que se atrevieran a disentir con el orden hegemónico. Incluso las fotografías como signo de represión remiten al contubernio de la NOA con las fuerzas estatales, pues dichas imágenes fueron idénticas a las que proporcionó la Policía Nacional para su difusión en la prensa (Comité de Defensa de los Derechos Humanos, 1969, p. 66). Por su parte, la lista de condenados a muerte es una táctica con doble función psicológica: aislar a las futuras víctimas del tejido social, acto que pueden realizar los propios "cuerpos dóciles" al evitar contacto con los defenestrados para preservar la vida propia; y generar incertidumbre al interior de los movimientos y organizaciones contestatarias. Este último punto se observa en el hecho de señalar a Mario Botzoc Hércules, líder estudiantil que tuvo nexos con las FAR, como delator de los "comunistas", intentando provocar desconfianza al punto de que su propio espacio de sociabilidad y militancia lo considere un traidor ${ }^{14}$.

De hecho, es muy probable que las amenazas y asesinatos de la NOA, como parte de una estrategia represiva generalizada, repercutieran en la ruptura entre el PGT y las FAR en enero de 1968; producto, en primera instancia, del rechazo ideológico del primero a la lucha armada como línea política a seguir para la revolución, pero también del temor a que sus miembros fueran ajusticiados por las fuerzas represoras. Al menos eso da a entender el documento de las FAR donde anunciaron la separación, señalando que, mientras la guerrilla afrontaba "la ofensiva contrarrevolucionaria más violenta y astuta", el PGT "pretendía dirigir desde sus escondites de la ciudad la lucha guerrillera, y con eso, recibiendo la sanción del fracaso militar con la muerte de centenas de compañeros y la muerte de casi 3,000 hombres del pueblo" (citado por Monsanto, 2013, pp. 408-409). Incluso individuos ajenos a estas pugnas se convirtieron en víctimas por el hecho de su parentesco familiar con los guerrilleros, siendo este el caso del hermano de César Montes, jefe de las FAR, al que la NOA torturó y asesinó (Galeano, 1967, p. 51).

La acción más importante que protagonizó la NOA fue el asesinato de Rogelia Cruz Martínez. Conocida por ser la "Miss Universo Guatemala" de 1958, Rogelia Cruz se incorporó a la lucha armada de las FAR a inicios de la

14 Al menos en este caso particular, el pretendido objetivo de la NOA no se cumplió. Meses después, en noviembre de 1967, Botzoc Hércules fue detenido por su activismo y un comando de las FAR lo liberó mientras estaba siendo procesado en un juzgado. Tras su liberación, formó parte de los intentos de reconstruir el frente guerrillero en el campo, muriendo en marzo de 1968 tras un enfrentamiento con el Ejército (Monsanto, 2013, p. 417). 
década de 1960, colaborando en el trabajo logístico-administrativo de la guerrilla en la capital. Por su activismo sufrió constantes amenazas de muerte por parte los escuadrones, hasta que en diciembre de 1967 fue secuestrada de su domicilio, apareciendo su cuerpo desnudo el 11 de enero de 1968 bajo un puente del Río Michatoya, en la entrada al municipio de Escuintla. De acuerdo con la necropsia que se le practicó, la exreina de belleza fue engrilletada, quemada con cigarrillos, violada, envenenada y cruelmente golpeada, lo que devino en un trauma cráneo-encefálico que le produjo la muerte. Contaba, además, con un embarazo de tres meses.

Si bien nadie reivindicó el siniestro, hay una serie de hechos que apuntan en dirección a la autoría de la NOA, con la complicidad de la Policía Judicial que efectuó el rapto. Quizás el más contundente fue la jactancia recurrente del coronel Zepeda de comentar en su círculo de allegados el cómo violó personalmente a Rogelia Cruz y ordenó su posterior asesinato (Comité de Defensa de los Derechos Humanos, 1969, p. 140). En ese sentido, no es casual que el gobierno solicitara de manera directa a Zepeda la investigación del crimen, en un probable intento de crear un "chivo expiatorio" para presentar a la opinión pública, o bien, para tomar reprimendas internas ante los excesos cometidos (Vázquez Medeles, 2012, p. 185). Lo cierto es que la intencionalidad disciplinaria de este crimen era contundente por la notoriedad pública de la víctima, pretendiendo impactar no solo a sus conocidos sino a toda la población. Como lo atestigua César Montes (2010 citado por Vázquez Medeles, 2012): "fue muy duro para nosotros, que la habíamos conocido personalmente, pero fue muy duro para el país, porque era decirle al país: 'Miren, ni a la reina de belleza vamos a respetar, ni a la Miss Guatemala, nada'” (p. 186).

El asesinato mereció la condena de gran parte de la sociedad civil y provocó una escalada de la violencia política que enfrentó a las FAR y a las fuerzas represivas con notorios impactos que trascendieron la política nacional. Leonardo Castillo Johnson, pareja sentimental de Rogelia, encabezó una serie de acciones punitivas contra los agregados militares de la embajada estadounidense. El 16 de enero, fueron acribillados en vía pública los coroneles John Webber y Harold Hauser. Webber era director de la misión militar estadounidense en Guatemala y sindicado como colaborador en la estrategia contrainsurgente que el Ejército aplicó sobre la guerrilla en la Sierra de las Minas; razones por las que las FAR reivindicaron el atentado acusando a Estados Unidos de promover los escuadrones que "estaban sembrando el terror y la muerte" en toda Guatemala (citado por Schlesinger \& Kinzer, 1982, pp. 275-276). Tras los hechos, el periodista y vicepresidente nacional Clemente Marroquín Rojas escribió una reflexión en la que señaló el asesinato de Rogelia Cruz como la causa del ataque contra los estadounidenses:

Inesperadamente ha brotado en el país la agresión y el crimen. En un solo día, ayer, se tuvo quizá la mayor cosecha de delitos. Ha sido una triste cadena: acaso derivada del inútil sadismo mostrado con una mujer: el de Rogelia Cruz 
Martínez. Este crimen causó indignación en todos los sectores políticos y hasta gente marcadamente hostil de las izquierdas condenaron la crueldad en el hecho criminal. Nosotros creemos que de esto se derivaron los nuevos actos que llenaron de pavor a la capital el día de ayer...

Lo que culminó esta pena, esta preocupación, fue el asalto a los militares norteamericanos, dos de los cuales perdieron la vida y dos están heridos. ¿Qué se buscó con esto? ¿Fueron o no fueron los izquierdistas? La lógica nos dice que sí, pero hay sus dudas a pesar de esa lógica. ¿Acaso no podría buscarse una situación dificultosa entre el gobierno de Guatemala y el de Estados Unidos? Esto es lo que piensan muchos, pero los más, atribuyen a las izquierdas tales hechos y todo, como revancha ante el crimen de Escuintla (Marroquín Rojas, 17 de enero de 1968, p. 2).

En sus memorias, Pablo Monsanto (2013), último comandante de las FAR hasta su disolución en 1996, confirmó las sospechas de Marroquín al reconocer la influencia del crimen contra Rogelia en la gestación de las acciones de la guerrilla:

El 11 de enero recrudece la represión anticomunista: aparece asesinada, después de ser vejada, violada cobardemente y vilmente torturada, Rogelia Cruz Martínez, hecho que conmueve e impacta nacional e internacionalmente y que, como reacción, provoca acciones de comandos urbanos revolucionarios, ajusticiando a militares estadounidenses asesores de la contrainsurgencia. Las gavillas de la MANO asesinan a varios intelectuales destacados académicamente, como Silvia Falla y Julio Camey Herrera. Ese mes se caracteriza por la confrontación brutal donde el terrorismo de ultraderecha se eleva a niveles difíciles de concebir. En esa confrontación bélica urbana muere Leonardo Castillo Johnson (pp. 410-411).

Con base en los recuerdos de Monsanto, es interesante observar cómo, a pesar del crecimiento en la espiral de violencia, los objetivos privilegiados de los escuadrones no cambiaron. Pese a la presencia ya visible de las guerrillas en la ciudad, estas organizaciones mantuvieron su enfoque represivo en la supuesta base social de los movimientos armados. A raíz del asesinato de los estadounidenses, Méndez Montenegro impuso el "estado de alarma" a nivel nacional, permitiendo la detención de personas sospechosas de alterar el "orden público" sin necesidad de alguna orden previa emanada del poder judicial. La entrada en escena de esta medida jurídica excepcional fortaleció el ambiente de impunidad con el que operaron los escuadrones, a la par que permitió a las fuerzas estatales contraatacar y aniquilar a varios miembros prominentes de las FAR, entre ellos Castillo Johnson. Lo cierto es que este entorno de violencia perpetua terminó socavando la legitimidad del régimen montenegrista ante el ciudadano común, debido a la aparente imposibilidad de acabar con el problema guerrillero y su ola de acciones mediáticas, cuya apoteosis fue el frustrado secuestro y asesinato del embajador estadounidense John Gordon Mein en agosto de 1968, como con el accionar 
indiscriminado de los escuadrones que asolaba a la sociedad civil (Sabino, 2008, T. II, p. 113) ${ }^{15}$.

Este nuevo panorama permite comprender la desaparición de la NOA en 1968, al resultar su existencia más contraproducente que benéfica para el gobierno. A grandes rasgos, la postura de Méndez Montenegro sobre los escuadrones fue dubitativa. Reconocía públicamente su existencia en los términos de "grupos clandestinos de ultraderecha" y "grupos bandoleros so capa de anticomunistas" (Comisión para el Esclarecimiento Histórico, 1999, T. II, p. 111), pero omitía el hecho de su conexión con las fuerzas de seguridad, limitándose a señalar su origen como una respuesta de la derecha política, en concreto el MLN, para defenderse de la guerrilla; versión oficial que se difundió en la prensa de tirada nacional y que implícitamente justificaba, mas no aprobaba, a los escuadrones como una estrategia de autodefensa civil contraguerrillera. Un documento anónimo de la época, titulado "La guerrilla y la anti-guerrilla en Guatemala", confirma esta interpretación del problema:

nos atrevemos a afirmar que en Guatemala existe ya un movimiento anti-guerrillero efectivo. ... Se han alcanzado objetivos claros, utilizando en la lucha contra las guerrillas, sus propias tácticas y sus mismos sistemas. Una fuerza armada de convicción política que se enfrenta, con la misma decisión, a un movimiento rebelde de convicciones ideológicas contrarias.

... Se organizan así espontáneamente diferentes grupos clandestinos antiguerrilleros ... luchan hombro con hombro organizaciones terroristas como la MANO BLANCA, la CRAG, la ROSA PURPURA, el RAYO, el Frente de Resistencia Nacional, la NOA y otros sectores de la iniciativa privada, todos los cuales demandan garantías y seguridad (s. f., citado por Aguilera Peralta, 1971, p. 4/20).

Así, al terror de la izquierda revolucionaria se contrapuso el terror anticomunista de la "ultraderecha", de la cual los escuadrones, irónicamente, eran su rostro más visible pese a la clandestinidad. Sin embargo, aunque desde la perspectiva del discurso el gobierno se mostró proclive a la persecución de los "dos demonios", las medidas tomadas en pro de dicho objetivo fueron claramente dispares. La razón es simple: la presión y sometimiento al estamento castrense. Recordemos que el "pacto secreto" firmado entre Méndez Montenegro y los militares dejó al gobierno con un mínimo margen de maniobrabilidad, permitiendo la descentralización de la represión para mantener inocua la imagen social de unos militares que delegaron el poder en medio de una crisis de legitimidad. En ese sentido, la represión gubernamental se enfocó primordialmente sobre

15 Para la prensa estadounidense, la muerte del embajador Mein mostró la angustiante situación vivida en Guatemala y, específicamente, por un gobierno civil presa de dos violencias igual de cruentas. Por ejemplo, la revista Life señaló que el crimen contra el diplomático se enmarcaba en una intensa ola de terror que ya había cobrado la vida de más de 2000 personas y que "tal matanza en Guatemala no viene solo de la guerrilla izquierdista en la ciudad y el campo, sino también de los recalcitrantes extremistas de derecha que les han estado activando bombas, secuestrando y matando. Desde 1966, este terror y contraterror tiene virtualmente paralizado al gobierno del presidente Julio César Méndez Montenegro, un liberal moderado a quien tanto la izquierda como la derecha les gustaría derrocar" (Eight Bullets in Guatemala, 6 de septiembre de 1968, p. 52A). 
las guerrillas y en un plano marginal en los escuadrones, aliados de los militares en el aniquilamiento de la disidencia política. Como señala Francisco Villagrán Kramer (2009), en su momento amenazado de muerte por la NOA:

No es que ambos sectores [Ejército y gobierno civil] estuvieren actuando de consuno o de acuerdo, sino que, para el Gobierno, era importante demostrar a la ciudadanía que actuaba con celo contra todos los que subvertían el orden público y que, en ese terreno, no figuraban únicamente las guerrillas ... . El hecho de tomar una decisión de esa naturaleza no dejaba de crear motivos de fricción entre los mandos militares y el gobierno civil. Para los altos jefes militares, los dirigentes de la Liberación [en referencia a los anticomunistas del MLN] eran amigos del Ejército y no estaban actuando contra él; en tanto que las guerrillas actuaban contra el Ejército, el capital y el Gobierno; en fin, contra el país. El Ejército requería en su lucha contra la subversión de amigos y aliados políticos (p. 378).

Ante las imposiciones castrenses, el gobierno recurrió a la creación de "chivos expiatorios" para calmar la indignación pública. Ocasionalmente, elementos policiacos preparaban un montaje en el que individuos que habían sido detenidos de manera arbitraria o por alguna infracción menor, eran presentados como integrantes de los escuadrones y procesados penalmente bajo esta acusación. Un caso asociado con la NOA permite ilustrar la cuestión. El joven Héctor Berger Mijangos, sin militancia política alguna, fue detenido tras salir de una fiesta por transitar la vía pública en estado de ebriedad. Conducido a las mazmorras de la Policía Nacional fue víctima de torturas por tres días hasta que se le acusó formalmente de distribuir propaganda de la NOA, usándose como prueba incriminatoria unos volantes de la organización que supuestamente cargaba el acusado. Tras varias peripecias, su abogado logró sacarlo de prisión al conseguir testigos que declararon cómo habían ocurrido los hechos en realidad (Galeano, 1967, p. 48). No debe obviarse que estos procedimientos, además de encubrir la identidad de los escuadrones, funcionaron también como dispositivos de control social, ya que probablemente los afectados no buscaron enrolarse en alguna actividad política posterior por temor a las represalias.

Sin embargo, esta situación fue difícil de mantener tras la escalada de la violencia política en 1968. Los secuestros y ejecuciones de personalidades con las que la sociedad tenía un profundo vínculo afectivo, como era el caso de Rogelia Cruz, obligaron al gobierno a tomar medidas serias contra los escuadrones, específicamente contra sus cabecillas y asociados prominentes. El detonante de estas acciones fue el secuestro del arzobispo Mario Casariego, perpetrado por la Mano Blanca en marzo. La unánime condena social por el crimen llevó a la pronta liberación del sacerdote y a que Méndez Montenegro destituyera a altos mandos militares vinculados a la represión clandestina y al escuadrón, entre ellos su ministro de Defensa, el coronel Rafael Arriaga Bosque, lo que a la postre llevó a la disolución de la organización. Similar destino atravesó la NOA, que cesó actividades una vez que el coronel Zepeda fue destituido de su cargo de Jefe del Servicio de Inteligencia del Ejército. 
La defenestración de los líderes de la NOA y del resto de los escuadrones no implicó, sin embargo, el fin de su trayectoria política o militar, lo que en buena parte explica por qué el estamento castrense no preparó un golpe de Estado contra Méndez Montenegro. Todos ellos fueron compensados con nuevos cargos, principalmente diplomáticos. Por ejemplo, Arriaga Bosque fue designado cónsul en Miami mientras a Zepeda se le nombró agregado militar de la embajada guatemalteca en Madrid. Por su parte, Oliverio Castañeda Paíz, el segundo al mando de la NOA, continuó con su carrera política y se convirtió en diputado del MLN en el Congreso Nacional. En otras palabras, las medidas tomadas por el gobierno fueron de forma y no de fondo, asegurando con ello la impunidad de los crímenes de los escuadrones y su posterior reactivación al final de su mandato en 1970 con la aparición, en plena contienda electoral, del Ojo por Ojo. El resurgimiento de la violencia de la "ultraderecha", sumado al inacabado problema de la guerrilla, fueron claves en la derrota en las urnas del partido gobernante, producto de un consenso social conservador que, deseoso de paz y orden, entregó el poder al general Carlos Arana Osorio. De cierta manera, el legado de terror y muerte de la NOA influyó para el regreso triunfal de los militares al control del Estado, esta vez por la vía democrática.

\section{A modo de conclusión}

La Nueva Organización Anticomunista fue uno de los principales exponentes de los escuadrones de la muerte paraestatales guatemaltecos de finales de la década de 1960. Uno de los aspectos más llamativos del complejo contrainsurgente que permitió la aparición de la NOA fue su gestación en un gobierno constitucional como el de Méndez Montenegro, cuya asunción al poder estuvo acompañada de una amplia expectación social sobre el regreso de la normalidad institucional y el fin de la violencia política y la represión que precedieron a su mandato. Sin embargo, la incapacidad del montenegrismo de atender la conflictividad social por medio de canales democráticos y apegados al derecho, en buena medida debido al sometimiento del gobierno civil a los designios militares, repercutieron para que este adoptara la represión como la respuesta más efectiva en el tratamiento de las disidencias político-sociales de la época. El resultado de esta decisión fue el establecimiento de un régimen defensor de la "seguridad nacional", bajo la premisa de que los sujetos a reprimir atentaban contra la armonía social y la integridad de la nación guatemalteca.

La presión castrense sobre Méndez Montenegro para mantener una imagen íntegra de las Fuerzas Armadas, sumado al fortalecimiento de las guerrillas en el campo, posibilitaron la aparición del complejo contrainsurgente, donde actores de diverso origen participaron de manera conjunta en la represión con escenarios claramente diferenciados, como lo constata la delimitación del accionar militar legal y del paramilitar ilegal en las zonas rurales para 
combatir a la guerrilla y sus potenciales bases campesinas. El embate de la represión obligó a los movimientos armados a trasladarse a las ciudades para reorganizarse y poder proseguir la lucha armada. Este hecho marcó la coyuntura que propició la creación de los escuadrones que, como la NOA, tuvieron la finalidad de reprimir a los simpatizantes y colaboradores de la guerrilla en el espacio urbano.

La composición social, las prácticas represivas y la selección de determinadas víctimas son los factores que permiten definir a la NOA como un escuadrón de la muerte paraestatal. La organización se constituyó en la clandestinidad con recursos y efectivos militares y policiacos, lo que le brindó gran capacidad y maniobrabilidad para la concreción de sus crímenes. Además, contó con el soporte civil de los militantes del anticomunista MLN, útiles en tareas de selección de blancos y delación. El accionar de la NOA consistió en amenazar y ejecutar los crímenes más atroces para propagar el terror en la sociedad guatemalteca y eliminar de raíz las disidencias. La potencialidad de sus actos criminales radicó en su manejo como propaganda represiva, llegando a niveles tan extremos como el difundir panfletos con fotografías de sus víctimas torturadas y asesinadas, tal como se observa en la Figura 1.

El espectro de las víctimas de la NOA fue amplio, aunque acotado a su vez por las lógicas del complejo contrainsurgente. Recordemos que los escuadrones no son fuerzas de combate antiguerrilleras, sino cuerpos de vigilancia y aniquilación de la población civil urbana. En ese sentido, los sujetos reprimidos fueron primordialmente individuos que simpatizaron con los movimientos armados o que pertenecieron a organizaciones, espacios y movimientos cuyas críticas al orden imperante los colocaron como representantes de la "subversión" comunista. Esta tendencia se mantuvo incluso en el momento de mayor escalada de la violencia que significaron los ataques de las FAR contra objetivos militares y diplomáticos en 1968. Además, las víctimas no fueron producto del azar, sino figuras reconocibles dentro de sus espacios de sociabilidad e, inclusive, por la sociedad en su conjunto para que los efectos propagandísticos del terror resultaran más efectivos, situación que quedó ilustrada en el asesinato de Rogelia Cruz.

La NOA profesó un imaginario social e identidad adscritas al anticomunismo nacionalista, que legitimó sus acciones como la respuesta necesaria para aniquilar la propagación del comunismo apátrida y extranjero que amenazaba la integridad de Guatemala. Esta interpretación implicó que la violencia fuera asumida como un acto de "purificación política", de limpieza políticosocial que procedió a la deshumanización de los "enemigos" de la nación en el discurso y en el ritual de violación de la vida humana concretado en las ejecuciones. Teniendo en cuenta esta lectura, los lemas de la organización revisados en este trabajo adquieren su pleno significado simbólico: la muerte de los "traidores" como redención de la vida del colectivo verdaderamente nacional. 
Lo cierto es que la existencia de la NOA fue un tanto efímera, obedeciendo su desaparición a las reconfiguraciones del sistema político más que a la extinción de la amenaza "comunista". La condena social a los crímenes de los escuadrones orilló a Méndez Montenegro a tomar cartas en el asunto para evitar mayores cuestionamientos a su gobierno, señalado de incompetente ante el problema de la violencia. La destitución o aprehensión de sus líderes marcó el fin de la NOA, aunque no de los escuadrones como estrategia represiva, que continuaron apareciendo en la década de 1970 en una clara señal de la sobrevivencia de un complejo contrainsurgente que descentralizó la represión.

Finalmente, es necesario interrogarse cuáles fueron las repercusiones políticas y sociales del operar de la NOA. A grandes rasgos, y recordando que sus acciones se articularon con las de otros actores del complejo contrainsurgente, podemos afirmar que cumplió con relativo éxito la tarea de contener las disidencias. La ruptura entre las FAR y el PGT, por ejemplo, no es comprensible del todo si no atendemos como variable de análisis el constante hostigamiento que la NOA y otros escuadrones ejercieron sobre los militantes del segundo por proveer de apoyo y simpatizantes a la guerrilla. Sin embargo, la repercusión más importante y grave se encuentra en la erosión de la legitimidad de las instituciones democráticas y constitucionales. La NOA ayudó a socavar cualquier posibilidad de establecer un estado de derecho, creando en su lugar un ambiente donde la incontenible violencia política generó un consenso social conservador que convocó nuevamente a los militares al poder, ante la incapacidad del gobierno civil de responder a las demandas de paz, orden y seguridad exigidas por la población. Aunque no haya sido un objetivo buscado por ella, la violencia que protagonizó terminó por relegitimar a las Fuerzas Armadas frente a una sociedad que, pocos años atrás, las había condenado al escarnio.

\section{Referencias}

Agamben, Giorgio. (2014). Estado de excepción. Buenos Aires: Adriana Hidalgo editora.

Aguilera Peralta, Gabriel Edgardo. (1971). La violencia en Guatemala como fenómeno político. Cuernavaca: Centro Intercultural de Documentación.

Aguilera Peralta, Gabriel Edgardo, Romero Imery, Jorge \& Torres-Rivas, Edelberto. (1981). Dialéctica del terror en Guatemala. San José: Editorial Universitaria Centroamericana.

Cáceres, Carlos. (1980). Aproximación a Guatemala. Culiacán: Universidad Autónoma de Sinaloa. 
Calvo Ospina, Hernando. (2008). Colombia, laboratorio de embrujos. Democracia y terrorismo de Estado. Madrid: Foca.

Cano, Ignacio. (2001). Policía, paramilitares y escuadrones de la muerte en América Latina. En Klaus Bodemer, Sabine Kurtenbach \& Klaus Meschkat (Eds.), Violencia y regulación de conflictos en América Latina (pp. 219-235). Caracas: Nueva Sociedad.

Casals A., Marcelo. (2013). La "larga duración" del autoritarismo chileno. Prácticas y discursos anticomunistas camino al Golpe de Estado de 1973. Revista de Historia y Geografía, (29), 31-54.

Comisión para el Esclarecimiento Histórico. (1999). Guatemala, memoria del silencio (T. I-XII). Guatemala: Oficina de Servicios para Proyectos de las Naciones Unidas.

Comité de Defensa de los Derechos Humanos. (1969). La Violencia en Guatemala. México, D. F.: Fondo de Cultura Popular.

Eight Bullets in Guatemala. (6 de septiembre de 1968). Life, 65(10), p. 52A.

Escuela de Guerra Especial del Ejército de los Estados Unidos. (1968). Guía para el planeamiento de la contrainsurgencia. En Alejandro del Corro (Comp.), Guatemala. La violencia (Volumen III, pp. 4/27-4/54). Cuernavaca: Centro Intercultural de Documentación.

Feierstein, Daniel. (2007). El genocidio como práctica social. Entre el nazismo y la experiencia argentina. Buenos Aires: Fondo de Cultura Económica.

Foucault, Michel. (2009). Vigilar y castigar. Nacimiento de la prisión. México, D. F.: Siglo Veintiuno Editores.

Franco, Vilma Liliana. (2002). El Mercenarismo corporativo y la sociedad contrainsurgente. Estudios Políticos, (21), 55-82.

Franco Restrepo, Vilma Liliana. (2009). Orden contrainsurgente y dominación. Bogotá: Siglo del Hombre Editores-Instituto Popular de Capacitación.

Galeano, Eduardo. (1967). Guatemala. País ocupado. México, D. F.: Editorial Nuestro Tiempo.

Garzón Rivera, Juana Marisol. (2016). Guerra y posguerra en El Salvador: rostros y legados de la violencia y el horror (1979-2009) (Tesis de Maestría en Historia Moderna y Contemporánea). Instituto de Investigaciones Dr. José María Luis Mora, Distrito Federal, México.

Jonas, Susanne. (1979). La nueva línea dura: estrategia norteamericana de los setentas. En Susanne Jonas \& David Tobis (Comps.), Guatemala: una historia inmediata (pp. 165-211). México, D. F.: Siglo Veintiuno Editores. 
López Larrave, Mario. (1979). Breve historia del movimiento sindical guatemalteco. Guatemala: Editorial Universitaria.

Marroquín Rojas, Clemente. (17 de enero de 1968). Hemos comenzado mal el año que se creyó mejor. La Hora, p. 2.

Melville, Thomas \& Melville, Marjorie. (1971). Guatemala, Another Vietnam? Middlesex: Penguin Books Ltd.

Monsanto, Pablo. (2013). Somos los jóvenes rebeldes. Guatemala insurgente. Guatemala: F\&G Editores.

Nueva Organización Anticomunista. (1968a). Advertencia Fatal a las F.A.R. En Alejandro del Corro (Comp.), Guatemala. La violencia (Volumen III, p. 4/302). Cuernavaca: Centro Intercultural de Documentación.

Nueva Organización Anticomunista. (1968b). Nueva Organización Anticomunista (N.O.A.) Al pueblo de Guatemala comunica. En Alejandro del Corro (Comp.), Guatemala. La violencia (Volumen III, p. 4/304). Cuernavaca: Centro Intercultural de Documentación.

Pueden portar armas Finqueros, Administradores y sus Representantes Legales. (7 de diciembre de 1966). Prensa Libre, p. 40.

Reyes Posada, Alejandro. (2007). Paramilitares en Colombia: contexto, aliados y consecuencias. En Gonzalo Sánchez \& Ricardo Peñaranda (Comps.), Pasado y presente de la violencia en Colombia. Medellín: La Carreta Editores y Universidad Nacional de Colombia, 353-361.

Rivas Nieto, Pedro y Rey García, Pablo. (2009). Bipolaridad y Guerra Fría en Iberoamérica. La Doctrina de Seguridad Nacional en el mundo de bloques. Espacios Públicos, 12(24), 161-175.

Sabino, Carlos. (2008). Guatemala, la historia silenciada (1944-1989) (Tt. I-II). Guatemala: Fondo de Cultura Económica.

Schlesinger, Stephen \& Kinzer, Stephen. (1982). Fruta amarga. La CIA en Guatemala. México, D. F.: Siglo Veintiuno Editores.

Sosa, Ignacio. (1997). Presentación. En Ignacio Sosa (Coord.), Insurrección y democracia en el circuncaribe (pp. 7-46). México, D. F.: Universidad Nacional Autónoma de México.

Vázquez Medeles, Juan Carlos. (julio-diciembre, 2012). El olvido en la memoria de Rogelia Cruz Martínez. Tzintzun. Revista de estudios históricos de la Universidad Michoacana de San Nicolás de Hidalgo, (56), 169-210. 
Villagrán Kramer, Francisco. (2009). Biografía política de Guatemala. Los pactos políticos de 1944-1970. Guatemala: Facultad Latinoamericana de Ciencias Sociales. 